\title{
Effectiveness of a Structured Teaching Programme on Knowledge Regarding Cervical Cancer among Women in Selected Wards of Malampuzha Panchayat at Palakkad District, Kerala
}

\author{
Josephine Jacquline Mary NI ${ }^{1 *}$, Kundapur R $^{2}$ and Dhanya Mol KK ${ }^{1}$ \\ ${ }^{1}$ SIMET College of Nursing, India \\ ${ }^{2}$ Nitte University, India
}

*Corresponding author: Josephine Jacquline Mary NI, SIMET college of Nursing, Nehru Nagar II ${ }^{\text {nd }}$ street Bharathi Nagar, Coimbatore District, India, Tel: 094465 29935; Email: josephinejacquline@gmail.com

\section{Review Article \\ Volume 3 Issue 2}

Received Date: February 02, 2019

Published Date: March 19, 2019

DOI: $10.23880 /$ nhij-16000182

\section{Abstract}

Globally cervical cancer ranks as the second most cancer in women and is one of leading causes of cancer related deaths for women in developed nations. The progression from normal cervical cells to dysplasia and then invasive cervical cancer appears to be related to repeated injuries to the cervix. The progression occurs slowly over years. A strong relationship exists between dysplasia and_HPV infection. This study is aimed to assess the knowledge regarding cervical cancer among women in selected wards of Malampuzha Panchayat at Palakkad district, Kerala, with the objectives to assess the existing knowledge_of women regarding cervical cancer, to develop and implement a structured teaching programme on cervical cancer, to assess the effect of structured teaching programme on cervical cancer and to find out the association between pre-test knowledge score on cervical cancer with selected demographic variables. The study adopted an one group pre-test- post-test design, and 60 samples were recruited by using a convenient sampling technique, followed by a structured questionnaire was used to collect the data prior to the structured teaching programme, given to the research participants and the post test was done after a period of one week. The data collected were analyzed using descriptive and inferential statistics. The findings of the study reveals pre-test assessment shows that $51.67 \%$ respondents had poor knowledge and $48.33 \%$ of the population had average knowledge. After education, Post-test assessment shows that no subjects have poor knowledge, 48.33\%have average knowledge and 51.67\% have good knowledge regarding cervical cancer. The mean post-test knowledge score (22\%) of the subjects was higher than the mean pre-test knowledge score $(9 \%)$ and the study was significant $(t=33.59 \mathrm{p}<0.05)$. There was a significant association between the pre-test knowledge scores and demographic variable on occupation.

Keywords: Cervical Cancer; Women; Teaching Programme 


\section{Nursing \& Healthcare International Journal}

\section{Introduction}

The cervix is the lower cylindrical part of the uterus .It is less mobile than body. It is about $2.5 \mathrm{~cm}$ long and is slightly wider in the middle than at either end. The lower part of the cervix projects into the anterior wall of the vagina which divides it into supra vaginal and vaginal parts. Cervical cancer remains a significant source of morbidity and mortality for women worldwide with more than 466000 women being diagnosed with invasive disease. Approximately 200000 deaths one attributed to progressive disease and concomitant complication yearly. HPV types 16 and 18 together causes about $70 \%$ of the cervical cancer. Cancer rates are expected to decline further with vaccines now being used for the prevention of HPV. Women with a history of cervical cancer should continue with screening as recommended by their health care provider for at least 20 years. Women who have been vaccinated against HPV needs to continue following the screening guidelines for her age group $[1,2]$.

\section{Statement of the Problem}

A descriptive study to assess the effectiveness of a structured teaching programme on knowledge regarding cervical cancer among women in selected wards of Malampuzha Panchayat at Palakkad District [3].

\section{Hypotheses}

$\mathbf{H}_{\mathbf{1}}$ : There will be significant difference between pre and post-test knowledge scores regarding cervical cancer.

$\mathbf{H}_{2}$ : There will be significant association between pre-test knowledge score and selected demographic variables.

\section{Objectives}

- To assess the existing knowledge of women regarding cervical cancer.

- To develop and implement a structured teaching programme on cervical cancer.

- To assess the effect of structured teaching programme on cervical cancer.
- To find out the association between pre-test knowledge score on cervical cancer and selected demographic variables.

\section{Conceptual Framework}

The conceptual framework adopted for the study is General System Theory by Ludwig Von Bertalanffy in 1968. This system model consists of the following phase like - input, process and output. Input refers to the women with three baseline characteristics such as age, religion, education, occupation, monthly income, marital status, number of pregnancies, family history of cancer, which may influence the knowledge level of women on cervical cancer.

\section{Process}

The present study adopted the following process.

- Knowledge of the women will be assessed by a structured knowledge questionnaire.

- A teaching programme on cervical cancer will be developed and implemented.

- Knowledge of the women will be assessed by using the same questionnaire to know the gain in the knowledge score.

\section{Output}

In the present study evaluation of the effectiveness of teaching programme on cervical cancer is the output [4].

\section{Feedback}

It is the process that provides information about the system's output and feedback as input. The higher knowledge score obtained by the women in the post test indicate that the teaching programme was effective in increasing the knowledge of women on cervical cancer. Lower scores indicate teaching programme was not effective in increasing the knowledge. Feedback is not assessed in this study [5].

\section{Environment}

The environment is the residence, setting and culture Figure 1. 


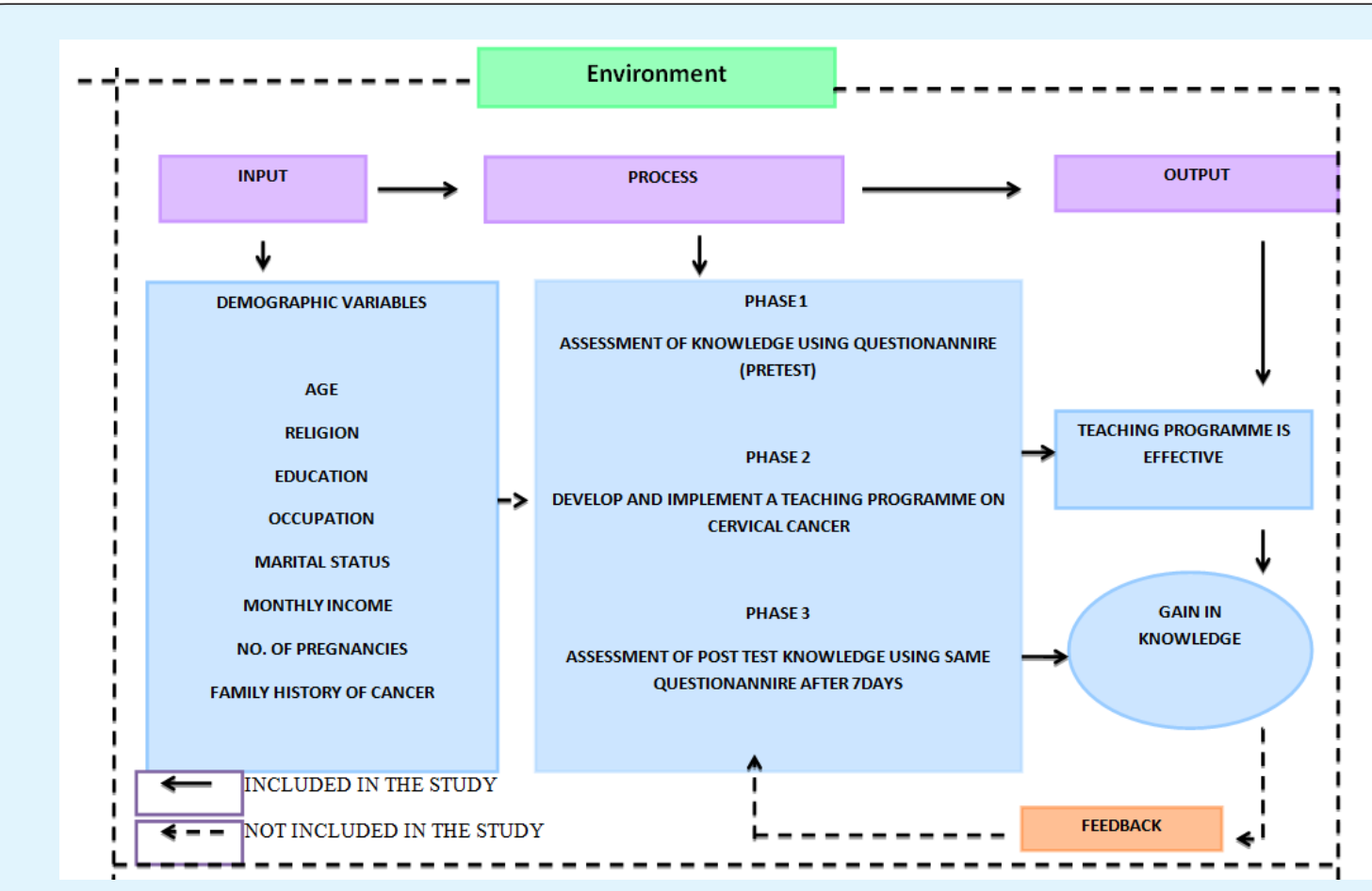

Figure 1: Conceptual framework based on Ludvig Von Bertalanffy's henesar system model (1968).

\section{Review of Literature}

A clinical survey was conducted to assess the knowledge, attitudes, and assumption of cervical cancer by women living in Maroua, the capital of the Far North Province of Cameroon. It was a single centre study. In a 1month period, 171 women were surveyed as to their socioeconomic status, sexual habits, prior knowledge of cervical cancer, its prevention, and their attitudes toward cervical cancer. Of 171 women, $48(28 \%)$ had prior knowledge of cervical cancer; they were classified as the "aware group" compared with 123 of 171 (72\%) women who were uninformed about cervical cancer and they were classified as the "unaware group" (UG). The UG of women tended to be single mothers, illiterate, housewives and had their first child before the age of $20(\mathrm{p}<0.005)$. Despite the awareness of cervical cancer by $28 \%$ of women, only a minority of them, 4 of $48(8.3 \%)$, underwent a preventive screening test. Only 71 of 171 (41.5\%) women stated that they would be having a screening test in the future. The awareness of cervical cancer by women in Cameroon is still inadequate. Thus they concluded that, to avoid deaths from cervical cancer, a curable and preventable disease, the need of an aggressive campaign to make Cameroonian women aware of cervical cancer and its prevention is needed.

\section{Methodology}

The study adopted a quantitative evaluative research approach with one group pre-test and post-test (01 X 02) research design to measure the effectiveness of the teaching programme on cervical cancer. The research population comprised of 60 married women of aged between 18 to 58 years in selected wards in the of Malampuzha Panchayat, Palakkad district by adopting convenient sampling technique. The tool was prepared with the help of various resources of literature and opinion from subject experts to ascertain the effectiveness and to bring about the 30 correct items in the questionnaire. Tool in English translated to Malayalam and was used for the research purpose. The Tool comprises of two sections.

Part 1 (Section A): Demographic characteristics include age, religion, education, Occupation marital status, monthly income, pregnancy rate and family history.

Part 2 (Section B): Tool consists of 30 multiple choice questions. Each correct answer was given 1 mark. Maximum score given for knowledge questions were 30 . After explaining the purpose of the study, informed consent was taken from the participants. The tool was administered to 60 women of age group 18-58yrs. The 


\section{Nursing \& Healthcare International Journal}

Pretested tools were collected and the teaching programme on cervical cancer given on the same day. The same questionnaire was given to the participants and the post test conducted after 7 days to assess the Effectiveness of the teaching programme. Data analysis was done using descriptive and inferential statistics. The findings of the pilot study revealed that the mean posttest knowledge scores of women were higher than the mean pre-test knowledge scores. There was a significant difference exist between the pre-test and post-test knowledge suggesting that the teaching programme was found to be effective.

\section{Major Findings of the Study}

Section A: Description of sample characters Tables 1, 2 \& 3.

\begin{tabular}{|c|c|c|c|}
\hline \multicolumn{4}{|c|}{$\mathrm{N}=60$} \\
\hline Sl. No & Demographic variables & Frequency & Percentage \\
\hline \multirow{5}{*}{1} & \multicolumn{3}{|c|}{ Age } \\
\hline & $18-28$ years & 4 & $6.67 \%$ \\
\hline & 28-38 years & 14 & $23.37 \%$ \\
\hline & $38-48$ years & 28 & $46.67 \%$ \\
\hline & 48-58 years & 14 & $23.33 \%$ \\
\hline \multirow{5}{*}{2} & \multicolumn{3}{|c|}{ Religion } \\
\hline & Hindu & 57 & $95 \%$ \\
\hline & Christian & 1 & $1.67 \%$ \\
\hline & Muslim & 2 & $3.33 \%$ \\
\hline & Others & 0 & 0 \\
\hline \multirow{5}{*}{3} & \multicolumn{3}{|c|}{ Educational status } \\
\hline & Primary & 33 & $55 \%$ \\
\hline & Secondary & 27 & $45 \%$ \\
\hline & Graduation & 0 & 0 \\
\hline & Post-Graduation & 0 & 0 \\
\hline \multirow{5}{*}{4} & \multicolumn{3}{|c|}{ Occupational status } \\
\hline & Govt. & 0 & 0 \\
\hline & Private & 3 & $5 \%$ \\
\hline & Housewife & 42 & $70 \%$ \\
\hline & Others & 15 & $25 \%$ \\
\hline \multirow{5}{*}{5} & \multicolumn{3}{|c|}{ Monthly income } \\
\hline & Below 2500 & 46 & $76.62 \%$ \\
\hline & $2500-5000$ & 12 & $20.04 \%$ \\
\hline & $5000-10000$ & 1 & $1.67 \%$ \\
\hline & Above 10000 & 1 & $1.67 \%$ \\
\hline \multirow{5}{*}{6} & \multicolumn{3}{|c|}{ Marital status } \\
\hline & Single & 1 & $1.67 \%$ \\
\hline & Married & 55 & $91.65 \%$ \\
\hline & Separate & 0 & 0 \\
\hline & Widowed & 4 & $6.68 \%$ \\
\hline \multirow{5}{*}{7} & \multicolumn{3}{|c|}{ Pregnancy rate } \\
\hline & 0 & 3 & $5.01 \%$ \\
\hline & 1 & 10 & $16.70 \%$ \\
\hline & 2 & 35 & $58.25 \%$ \\
\hline & Above 2 & 12 & $20.04 \%$ \\
\hline \multirow{2}{*}{8} & \multicolumn{3}{|c|}{ Family history } \\
\hline & Yes & 4 & $6.68 \%$ \\
\hline
\end{tabular}




\section{Nursing \& Healthcare International Journal}

\begin{tabular}{|c|c|c|c|}
\hline \multirow{3}{*}{} & No & 46 & $76.62 \%$ \\
\cline { 2 - 4 } & Not known & 9 & $15.03 \%$ \\
\cline { 2 - 4 } & Doubtful & 1 & $1.67 \%$ \\
\hline
\end{tabular}

Table 1: Frequency and percentage distribution of subjects on selected demographic variables.

Section B: Knowledge Assessment: Pre-test knowledge shows that $51.67 \%$ have poor knowledge and $48 \%$ have average knowledge. Post-test knowledge shows that
$51.67 \%$ have good knowledge and $48 \%$ have average knowledge

Section C

$\mathrm{N}=60$

\begin{tabular}{|c|c|c|c|c|}
\hline \multirow{2}{*}{ Level of knowledge } & Pre-test & Post-test & \multirow{2}{*}{ Frequency } & \multirow{2}{*}{ Percent } \\
\cline { 2 - 5 } & Frequency & Percent & 0 & $0 \%$ \\
\hline Poor & 31 & $51.67 \%$ & 29 & $48.80 \%$ \\
\hline Average & 29 & $48.33 \%$ & 31 & $51.67 \%$ \\
\hline Good & 0 & $0 \%$ & $\mathbf{1 0 0} \%$ \\
\hline Total & $\mathbf{6 0}$ & $\mathbf{1 0 0 \%}$ & $\mathbf{6 0}$ & $\mathbf{1 0}$ \\
\hline
\end{tabular}

Table 2: Distribution of subjects based on comparison of pretest and post-test knowledge scores.

It reveals pre-test assessment shows that $51.67 \%$

respondents had poor knowledge and $48.33 \%$ of the

population had average.

Section D: Effectiveness of Structured Teaching Programme.

$\mathrm{N}=60$

\begin{tabular}{|c|c|c|c|c|c|}
\hline Test & Mean & SD & Mean improvement in knowledge & SD & t value \\
\hline Pretest & 9 & 2.84 & 13 & $33.59^{*}$ \\
\hline & & & 13 & \\
\hline Postest & 22 & 3.06 & \multicolumn{2}{|l}{} \\
\hline
\end{tabular}

$\mathrm{df}=59 \quad$ *Significant $\quad \mathrm{P}<0.05$

Table 3: Significance of difference between pre-test and post-test knowledge scores.

Computed $t$ value is 33.59, the tabled value of $t$ at 0.05 level is 1.671 and at 0.01 level is 2.391.Calculated value is higher than tabled value. Hence research hypothesis is retained. It shows there is a significant difference in mean pre-test knowledge and mean post-test knowledge and increase in mean score shows that structured teaching programme was effective.
Section E: Association between pre interventional knowledge scores and selected demographic variables

From the analysis, it is clear that there was significant association between pre interventional knowledge and selected demographic variables such as occupation. There was no association between knowledge score and selected demographic variables like age, religion, educational status, monthly income, marital status, pregnancy rate, family history Table 4 .

\begin{tabular}{|c|c|c|c|c|}
\hline Demographic variable & \multicolumn{3}{|c|}{ Pre-test knowledge score frequency } & \multirow{2}{*}{ Chi-square value } \\
\hline Occupational status & Poor & Average & Good & \multirow{2}{*}{$9.064^{*}$} \\
\hline Govt & 0 & 0 & 0 \\
\hline Private & 2 & 1 & 0 \\
\hline House wife & 19 & 23 & 0 \\
\hline Others & 11 & 4 & 0 & \\
\hline
\end{tabular}

$\mathrm{df}=59 \quad$ *Significant $\quad \mathrm{P}<0.05$

Table 4: Distribution of subjects based on pre-test knowledge score and occupation.

Panchayat at Palakkad District, Kerala. Nurs Health Care Int J 2019, 3(2): 000182. 


\section{Nursing \& Healthcare International Journal}

From the table, it is clear that the calculated $\chi^{2}$ value is 9.064 and table value is 7.82 which is less than the calculated value at 0.05 level of significance. $\mathrm{H}_{0}$ is rejected and hypothesis $\mathrm{H}_{2}$ is accepted. Hence there is an association between pre-test knowledge score and occupational status.

\section{Discussion}

In this study, before the teaching programme $48.33 \%$ of the respondents showed an average and $51.67 \%$ of subjects showed poor knowledge about cervical cancer. $51.67 \%$ of the subjects showed good knowledge about cervical cancer after the structured teaching programme. This study is supported by the study conducted by Harbans Kaur Anita Rani (2017) the effect of structured teaching programme regarding cervical cancer among women aged 30-40 years in selected rural district of Jalandhar which shows that the pre-test mean knowledge score of experimental group was 12.43 and control group was 11.66 and the post-test mean knowledge score of experimental group was 29.43 and control group was 12 . The knowledge of rural women among experimental group were statistically significant at $<0.001$. As structured teaching programme had significant improvement in the knowledge in mean score from pretest mean score (12.43) to post-test mean score (29.53).

There was no association between knowledge score and selected demographic variables like age, religion, monthly income, marital status, pregnancy rate, family history. There was significant association between pretest score and occupation.

In the present study, totally 60 women of age group between 18-58 years were selected from the selected ward of Malampuzha panchayat. A structured questionnaire with 30 questions are used for data collection followed by structured teaching programme to improve the knowledge regarding cervical cancer.

- Majority of the (70\%) subjects are housewives.

- Majority of the $(76.62 \%)$ had a monthly income less than 2500.

- Majority of the (91.65\%) subjects are married.

- Majority of the (58.25\%) subjects had pregnancy rate of 2 .

- Most of the subjects (76.62\%) had no family history of cancer.

There was a significant association between pre-test score and occupation.

\section{Nursing Implication}

The implication of the study could be discussed in four main areas namely, nursing practice, nursing research, nursing education and nursing administration.

\section{Implication for Nursing Practice}

Nurse should be able to provide preventive, promotive and curative care for the women through proper health education regarding cervical cancer [6-11].

\section{Implication for Nursing Research}

The information contained in the present study can be valuable source of data for the future researchers which will help them in conducting research with large samples with different setting.

\section{Implications for Nursing Education}

The student should be taught about the cervical cancer in detail and they should be provided information on cervical cancer on the basis of various research findings. The students are also taught about the diagnostic measures and prevention of cervical cancer and thereby reducing the incidence and mortality of cervical cancer.

\section{References}

1. HPV vaccine.

2. Honor Whiteman (2018) Cervical cancer the importance of regular screening.

3. Bobdey S, Sathwara J, Jain A, Balasubramaniam G (2016) Burden of cervical cancer and role of screening in India 37(4): 278-285.

4. Harsha Kumar H, Tanya S (2014) A Study on Knowledge and Screening for Cervical Cancer among Women in Mangalore City. Ann Med Health Sci Res 4(5): 751-756.

5. (2018) Cervical cancer by Cancer Institution.

6. Annama Jacob (2012) A comprehensive textbook of midwifery and Gynecological Nursing. $3^{\text {rd }}$ (Edn.), Jaypee Publication, pp: 812.

7. Arulkumar S, Sivanesarathram V, Chatterer A, Kumar $P$ (2011) Essential of Gynecolog. $2^{\text {nd }}($ Edn.), Jaypee Publications, pp: 480-488. 


\section{Nursing \& Healthcare International Journal}

8. Hacker, Gambone, Hobel (2016) Essential of Obstetrics and Gynecology. $5^{\text {th }}$ (Edn.), Elsevier Publications, pp: 402-411.

9. Ashwini Bhalerao Gandhi, Paragraph Biniale (2009) Gynecological Manual of adolescent girls. Jaypee Publications, pp: 456.
10. Shalini Rajaram, Sumitha Mehta (2008) Advances in Obstetrics and Gynecology. Jaypee Publications, pp: 448.

11. Sreedevi A, Javed R, Dinesh A (2015) Epidemiology of cervical cancer with special focus on India. Int J Womens Health 7: 405-414. 